\title{
Comparative meta-analysis of the impact of offshore marine mining on macrobenthic communities versus organic pollution studies
}

\author{
Candida Savage $^{1, *}$, John G. Field ${ }^{1}$, Richard M. Warwick ${ }^{2}$ \\ ${ }^{1}$ Marine Biology Research Institute, University of Cape Town, Rondebosch 7701, South Africa \\ ${ }^{2}$ Plymouth Marine Laboratory, Prospect Place, West Hoe, Plymouth PL1 3DH, United Kingdom
}

\begin{abstract}
The phylum-level meta-analysis approach has been proposed as a way of comparing geographically different areas along a common scale of disturbance. However, the training data set which establishes the scale of disturbance and all subsequent studies using the approach have been exposed to some sort of organic or inorganic pollution. Using macrobenthic communities subjected to a short-lived but intense physical disturbance from offshore mining off the west coast of Southern Africa, we tested the applicability of the meta-analysis approach for assessing the severity of disturbance in physically disturbed communities. The positioning of the original data set along a primary axis of disturbance was maintained; however, a second significant separation, along the vertical axis, distinguishes between macrobenthic assemblages from southern Africa and the NE Atlantic Shelf. The southern African samples are characterised by a larger proportion of Crustacea, and in the case of mined samples Mollusca, whereas the NE Atlantic data contain relatively more Echinodermata in the unpolluted samples and are dominated by Annelida in the organically enriched areas. The proportion of annelids decreased by about $50 \%$ in mined areas compared to the non-mined areas and the NE Atlantic samples. Conversely, bivalves and gastropods exhibited a notable increase in proportion in the mined patches compared to the adjacent non-mined areas, possibly as a result of their preferential ability to survive the mining process or their better ability to recolonise after mining, or an interplay of both factors. The mining activity may result in the selection of species for their physical robustness and tolerance to mining rather than their resistance to pollution in the conventional sense. The failure of the meta-analysis to ordinate the mined samples along the primary horizontal axis of disturbance, as defined by Warwick \& Clarke's original study (1993, Mar Ecol Prog Ser 92:221-231), does not reflect a failure of the meta-analysis to detect disturbance, but rather shows that the primary axis is strongly determined by the opportunistic species characteristic of organically enriched areas. It appears that phylum-level meta-analysis is better suited to assessing the impact of organic and chemical pollution on an ocean-basin scale than it is to physical disturbance caused by offshore mining.
\end{abstract}

KEY WORDS: Meta-analysis $\cdot$ Physical disturbance $\cdot$ Macrobenthos $\cdot$ Offshore mining $\cdot$ Southern Africa

Resale or republication not permitted without written consent of the publisher

\section{INTRODUCTION}

The analysis of changes in soft-bottom macrobenthic community structure has been widely used for detect-

\footnotetext{
*Present address: Systems Ecology Department, Stockholm University, 10691 Stockholm, Sweden.

E-mail: candida@system.ecology.su.se
}

ing and monitoring the biological effects of human activities in the marine environment. The inherent multivariate nature of macrobenthic communities (Field et al. 1982) and the large variations in species composition from geographically distant areas (Morrisey et al. 1992) have daunted comparative studies across wide geographical areas. Furthermore, a high degree of standardisation in terms of taxonomic rigour 
would be required to compare macrobenthic communities from independent studies. Therefore, changes in benthic communities have typically been constrained to comparisons made relative to local controls. However, to attach a value judgement to any community change, environmental managers may want to assess the severity of disturbance of a species assemblage visà-vis other disturbance studies on a broad scale.

Intuitively, species-independent methods such as distributional (Warwick et al. 1987, Clarke 1990, Warwick \& Clarke 1994) and univariate analyses (Warwick 1986, Beukema 1988, Reizopoulou et al. 1996) would be preferable for describing benthic community change on a common scale. However, multivariate techniques have shown to be particularly sensitive in detecting even subtle shifts in community structure (Gray et al. 1990, Warwick et al. 1990, Warwick \& Clarke 1991, Dawson Shepherd et al. 1992, Cao et al. 1996) and have enjoyed an upsurge in environmental impact studies in recent years. One of the drawbacks of multivariate techniques is that they detect differences between communities, but it has been difficult to attach a scale of disturbance to observed community change.

Warwick \& Clarke's (1993) meta-analysis approach was an attempt at gauging the relative severity of disturbance of community change whilst retaining individual species responses, and as such, provides a multivariate method for comparative analyses. Metaanalysis is the statistical analysis of a large collection of analysis results from individual studies for the purpose of integrating the findings (Glass 1976). While the use of meta-analysis is widespread in the medical and social sciences, only recently has it been applied to ecological questions (Adams et al. 1997, Downing et al. 1999, Gurevitch \& Hedges 1999, Osenberg et al. 1999). The approach is suggested to enhance the inferential capabilities in damage assessment studies (Skalski 1995), enabling disturbance to be appraised against a scale of perturbation.

Large-scale spatial heterogeneity of macrofauna can be overcome by working at taxonomic levels higher than species. Several studies have endorsed the aggregation of data to higher taxonomic levels by showing that disturbance effects on soft-bottom macrobenthos are often detectable with multivariate methods at very high taxonomic levels (Heip et al. 1988, Herman \& Heip 1988, Warwick 1988a,b, Ferraro \& Cole 1990, Gray et al. 1990, Warwick 1993, Somerfield \& Clarke 1995, Savage 1996, Vanderklift et al. 1996, Bowman \& Bailey 1997, Olsgard et al. 1997). By working at the phylum level, Warwick \& Clarke's (1993) meta-analysis approach essentially overcomes the confounding factors of taxonomic uniqueness of different geographical areas.
Using a range of case studies representing varying degrees of disturbance and some putatively undisturbed sites, Warwick \& Clarke (1993) were able to assess the relative severity of disturbance of 50 stations from 8 locations on the NE Atlantic Shelf. Nonmetric Multi-Dimensional Scaling (MDS) ordination produces a configuration with the principal horizontal axis representing a scale of disturbance. Interpretation of the ranking of sites as a reflection of increasing disturbance is based on information from univariate and graphical distributions, and contaminant concentrations (Warwick \& Clarke 1993). In Warwick \& Clarke's (1993) original data set, the most organically enriched sites are located to the extreme right of the plot and the undisturbed samples are clustered to the left. The authors proposed that their study can be used as a training data set against which the community status from new locations can be assessed, with their relative positions on the horizontal axis being a measure of the relative severity of disturbance.

Warwick \& Clarke's (1993) baseline study used samples only from a single geographical region, namely the NE Atlantic Shelf, and most of the disturbed samples were subjected to organic enrichment or other chemical pollution. The approach has been verified in studies of macrobenthic communities in organically enriched bays in Central Chile (Tam \& Carrasco 1997), in a tropical estuary in the West Indies impacted by oil (Agard et al. 1993) and in estuaries in the Gulf of Cádiz, Spain, exposed to organic and inorganic pollution (Drake et al. 1999). MDS makes fewer assumptions about the nature of the data than most ordination techniques and can usually be applied to a variety of situations (Kenkel \& Orloci 1986). Nevertheless, one feature of multivariate analyses is that the dominance of a few major phyla will largely determine the configuration of the ordination plots and it remains to be tested therefore whether Warwick \& Clarke's (1993) baseline study can be used for comparative analyses of physically disturbed macrobenthic communities.

The primary aim of the current study is to assess the more general applicability of the phylum-level metaanalysis approach for appraising disturbance of macrobenthic communities exposed to types of disturbance other than chemical pollution. Macrobenthic samples collected from an offshore diamond mining area off the west coast of southern Africa, which have been subjected to physical disturbance due to the mining operation, were compared to the baseline data from the NE Atlantic Shelf. In doing so, we also compare macrobenthic communities from another geographical region, namely the continental shelf off the southern African coast. 


\section{METHODS}

Description of the mining operation. Offshore diamond mining is centred around Oranjemund at the mouth of the Orange River that divides Namibia and South Africa. Offshore mining takes place on the continental shelf in waters between 85 and $200 \mathrm{~m}$ below mean sea level, with the primary focus at 100 to $130 \mathrm{~m}$ depth. The mining process uses high-powered air-lift suction to deliver sediment to the anchored mining vessel. The sediment is screened onboard for diamonds and the discarded gravel and fine sediment then released overboard. The fine sand component (250 to $125 \mu \mathrm{m}$ ) remains suspended in the water column and prevailing currents gradually disperse them over a wider area.

Study area and sampling. Sampling was conducted 20 to $30 \mathrm{~km}$ off the Namibian coast just north of the Orange River (Fig. 1). Six sampling stations were selected: 5 stations that had been mined at different times in the past and a non-mined reference station. The mined stations represented various stages of post-mining recovery from less than 1 mo to over $3 \mathrm{yr}$ of recovery before sampling was conducted. Station 1 provided a 'beforeand-after' reference area, being non-mined when it was sampled in 1994 and mined 1 mo before the second sampling cruise in 1995. Station 2 is a reference station that has never been mined. Stations 1 to 4 are situated at $130 \mathrm{~m}$ depth and are separated from Stations 5 and 6 by approximately $30 \mathrm{~km}$. Stations 5 and 6 are at a mean depth of $110 \mathrm{~m}$.

The 6 stations were sampled over 2 consecutive yr, in June 1994 and February 1995. During the first sampling cruise, ten $0.2 \mathrm{~m}^{2}$ Van Veen grab samples were taken at each station, with a total of 60 samples. The same 6 stations were revisited 9 mo later when an additional 6 samples were taken per station, totalling a further 36 samples. At the 5 mined sampling stations, several grab samples were taken within mined areas and several from adjacent non-mined areas. The position of each grab sample was plotted onto mining maps by a surveyor from De Beers Marine within $20 \mathrm{~m}$ accuracy, using a satellite navigational Global Positioning System (GPS) and making allowances for drift of the grab. In addition, sediment samples provided clues as to whether or not a sample was taken within a mined area. Particle size analysis showed that the non-mined sediment was a stratified sequence of gravels ( $2 \mathrm{~mm}$ to $500 \mu \mathrm{m}$ ) overlain by fine to very fine sand (250 to $63 \mu \mathrm{m}$ ) (Rogers 1995). As a consequence of mining, the stratified sequence is disturbed and the sediment is returned to the seafloor as a mixture of sediment sizes and types (Rogers 1995). By concurrently plotting the sample positions on maps of the mined areas and checking the sediment size frequency distribution, each grab sample was classified a priori as mined or non-mined. Grab samples which fell near the border of a mined area or whose positions could not be accurately pinpointed were excluded from the study.

Each grab sample is represented by a 2-digit number: the first digit represents the station (1 to 6) and the second digit represents the replicate taken at a particular station; for example, 6.4 means the fourth replicate taken at Station 6. Grab samples preceded by 'A' refer to samples collected during the first cruise in 1994; similarly, samples preceded by 'B' denote those collected during the second cruise in 1995. Replicates are numbered according to the grab attempt and are therefore not necessarily consecutive.

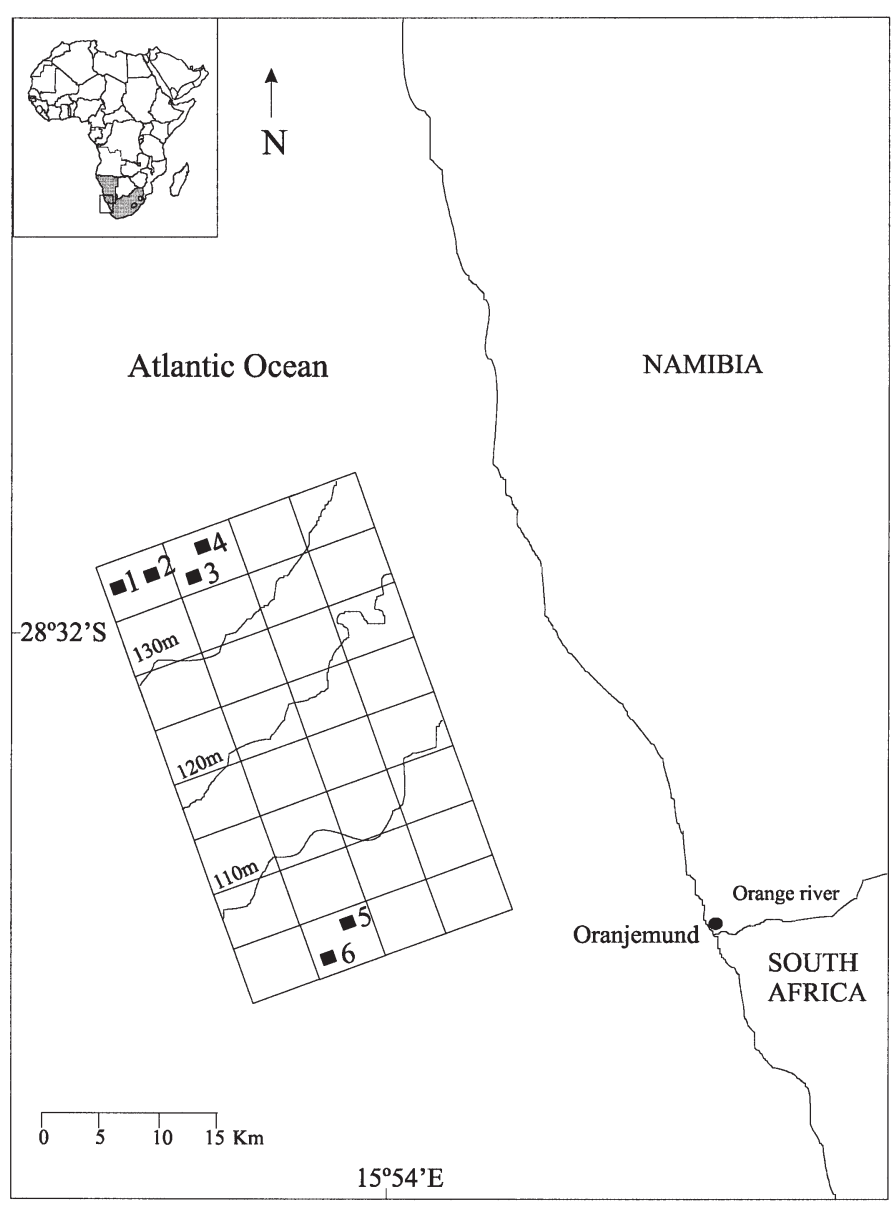

Fig. 1. Study area off the west coast of southern Africa, showing the 6 sampling stations in a grid drawn to scale where each block represents $5 \times 5 \mathrm{~km}\left(25 \mathrm{~km}^{2}\right)$. The stations are located along a depth gradient with the northern stations, 1 to 4 , located at $130 \mathrm{~m}$ and the southern stations, 5 and 6 , located at $110 \mathrm{~m}$ 
Benthic faunal analysis. Core subsamples were collected from each grab sample for particle size analysis. Grab samples were wet sieved through a series of nested sieves and all organisms retained on the $1 \mathrm{~mm}^{2}$ sieve were fixed in $10 \%$ formalin and kept for analysis. Empty mollusc shells and organisms considered dead at the time of sampling were excluded from the study. In the laboratory, the macrofauna were sorted, transferred to $1 \%$ propylene phenoxytol, identified to the lowest possible taxon using a dissecting microscope and counted. Samples were blot-dried to remove excess liquid and weighed. Molluscs were weighed in their shells.

Numerical analysis. Impoverished samples, with fewer than 5 species per grab sample, and samples that could not be accurately classified, were omitted from the analysis. Of the 96 grab samples collected from southern Africa, 89 were included in the analysis: 30 from mined areas and 59 from non-mined areas. Species abundance and biomass data were aggregated to phylum level following the classification of Howson (1987). The phyla data were merged into a 'production' matrix using the allometric equation, $P=(B / A)^{0.73} \times A$, where $P$ is estimated production, $B$ is biomass and $A$ is the abundance of a species (Brey 1990). The data were standardised by expressing the production of each phylum as a proportion of the total production for each sample. The southern African production data were combined with Warwick \& Clarke's (1993) baseline study data and a non-metric MDS ordination performed using this expanded data set.

The data were analysed using numerical methods outlined by Field et al. (1982) and the software package PRIMER (Plymouth Routines In Multivariate Ecological Research), Version 4.0 (Clarke \& Warwick 1994). Similarities between every pair of samples in terms of their phyletic composition are calculated using the Bray-Curtis measure of similarity (Bray \& Curtis 1957) and 4th-root transformed production data. The similarity matrix forms the basis for the clustering and ordination analyses. Non-metric multi-dimensional scaling (MDS) ordination (Kruskal \& Wish 1978) produces a 2-D plot which represents the best possible reconciliation between all inter-sample distances and the relative distance between points is a measure of their relative degree of (dis)similarity. A stress function between 0 and 1 is presented in each plot which is a measure of how well the sample relationships are represented in the 2-D ordination.

PRIMER V.4 is limited to a $125 \times 125$ similarity matrix and to aid visual interpretation of the community patterns, the southern African data were treated as 5 separate data sets and 5 ordinations performed. MDS ordinations were performed on the NE Atlantic data combined with: (1) the 30 mined samples from both cruises; (2) the 59 non-mined samples, to discern any inherent differences between the 2 locations (NE Atlantic and southern Africa); the combined mined and non-mined data from (3) the first and (4) the second sampling cruise; (5) the 'before-and-after' mining data from Station 1.

The mined samples were collected from areas with different times of post-mining recovery, which have been arbitrarily divided into 4 categories: (I) just mined (less than 1 mo before benthic sampling); (II) mined less than 1 yr before sampling (all samples classified in this category had 7 to 9 mo of recovery); (III) between 1 and $2 \mathrm{yr}$ of recovery; and (IV) greater than $3 \mathrm{yr}$ of recovery before benthic sampling (Table 1). The 4 categories of post-mining recovery were superimposed on the MDS plot of mined samples to assess whether there is any change in community composition with increasing time of recovery.

Statistical differences between sites were determined using the one-way ANOSIM (analysis of similarities) randomisation permutation test in PRIMER with 5000 permutations (Clarke \& Green 1988). Two separate ANOSIM tests were performed: on the NE Atlantic data versus the mined samples, and the NE Atlantic data versus the non-mined samples from both cruises. To assess which phyla contributed the most weighting in terms of the average Bray-Curtis dissimilarity between the southern African samples and the NE Atlantic Shelf samples, the program SIMPER (Similarity Percentages) (Clarke 1993) was performed on the 4 th-root transformed mined and non-mined data, respectively.

Table 1. Temporal states of post-mining recovery for the 30 mined samples at the time of sampling. Samples are grouped into recovery periods of (I) mined 1 mo prior to sampling, (II) mined 7 to 9 mo previously, (III) mined 12 to 24 mo previously, and (IV) greater than 36 mo previously. The prefix 'A' denotes samples collected during the first (1994) cruise, and 'B' denotes samples collected during the second (1995) cruise

\begin{tabular}{ll} 
Recovery status at time of sampling & \multicolumn{1}{c}{ Sample number } \\
\hline I. Mined 1 mo previously & $\mathrm{A} 3.2, \mathrm{~A} 3.4, \mathrm{~B} 1.1, \mathrm{~B} 1.11, \mathrm{~B} 1.14, \mathrm{~B} 1.17, \mathrm{~B} 3.1, \mathrm{~B} 3.2$ \\
II. Mined 7 to 9 mo previously & $\mathrm{A} 4.2, \mathrm{~A} 4.7, \mathrm{~A} 4.8, \mathrm{~A} 4.10, \mathrm{~B} 1.5, \mathrm{~B} 3.3, \mathrm{~B} 3.4, \mathrm{~B} 3.7$ \\
III. Mined 12 to 24 mo previously & $\mathrm{A} 5.3, \mathrm{~B} 4.2, \mathrm{~B} 4.6, \mathrm{~B} 4.8, \mathrm{~B} 4.9, \mathrm{~B} 4.13, \mathrm{~B} 4.14, \mathrm{~B} 4.15$ \\
IV. Mined $>$ 36 mo previously & $\mathrm{A} 6.8, \mathrm{~A} 6.9, \mathrm{~A} 6.10, \mathrm{~B} 6.1, \mathrm{~B} 6.3, \mathrm{~B} 6.5$
\end{tabular}



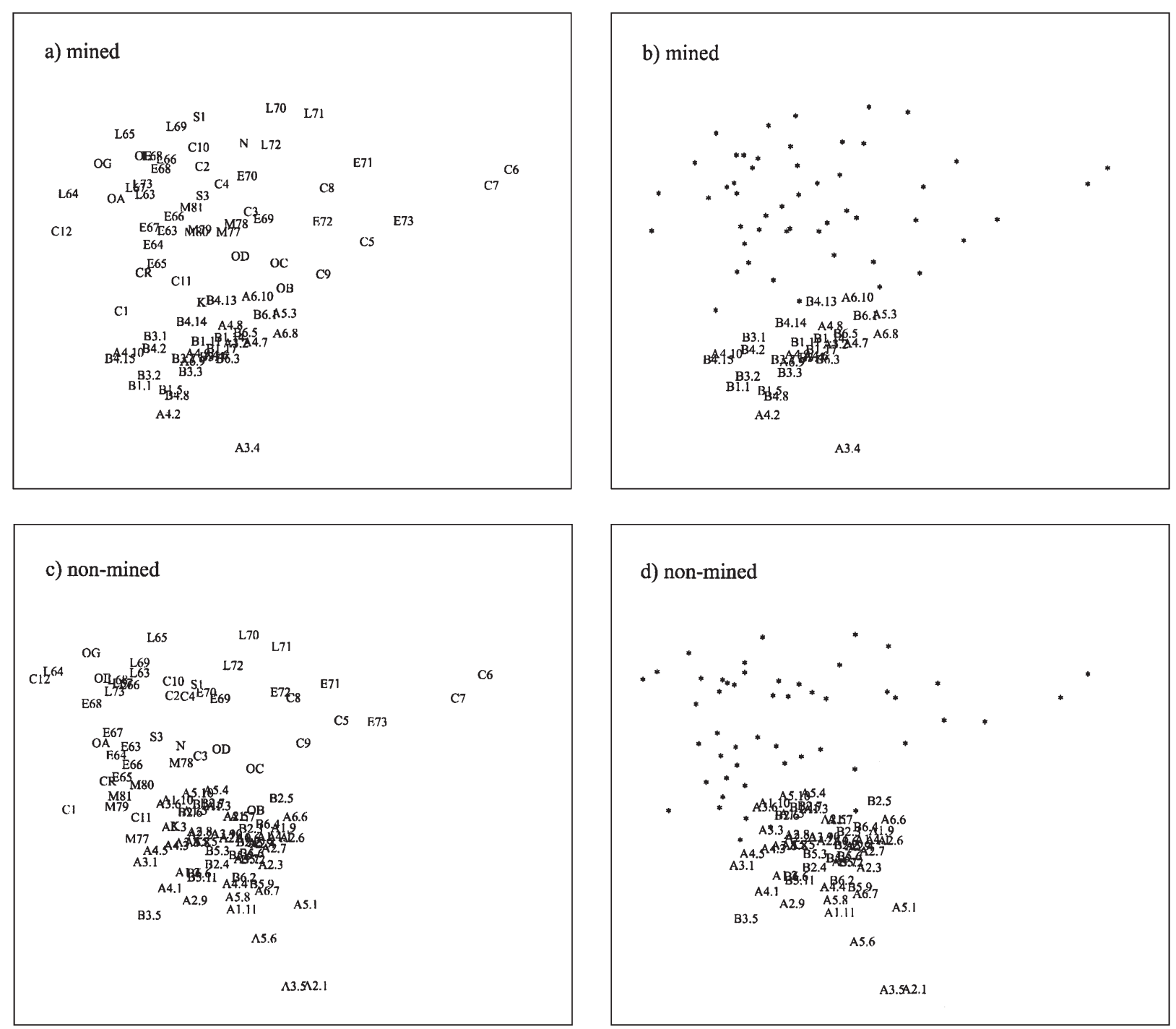

Fig. 2. MDS ordinations of the phylum-level production data from the original NE Atlantic samples, with Clyde (C1 to C12); Linnhe (L63 to L73); Eil (E63 to E73); Oslofjord (OA to OG); Morlaix (M77 to M81); Skagerrak (S1, S3); Northumberland (N); Carmarthen (CR) and Kiel (K) (Warwick \& Clarke 1993) combined with the southern African samples. (a) Mined samples; (b) mined samples with only the southern African samples identified (stress $=0.18$ ); (c) non-mined samples; (d) non-mined samples with only the southern African samples identified (stress = 0.17)

\section{RESULTS}

The results are presented in 2 forms, firstly with all the stations identified and secondly with the southern African samples identified and the original 50 samples from the NE Atlantic Shelf represented as asterisks so that the relative positions of the southern African samples can be clearly seen (Fig. 2). The macrobenthic communities from southern Africa span approximately halfway across the horizontal axis of disturbance, suggesting that compared to the NE Atlantic communities used in Warwick \& Clarke's (1993) study, some of the samples are 'undisturbed' to 'moderately disturbed'.
No samples extend to the extreme right of the disturbance axis where the grossly polluted samples collected from the centre of the Clyde sewage-sludge dump-ground in Scotland, C6 and C7, are positioned (Pearson 1987). An interesting finding is that the mined (Fig. 2a,b) and the non-mined (Fig. 2c,d) samples spread along a very similar range of the horizontal axis. Within the group of mined and non-mined samples, there is no clear distinction between the 6 stations or between samples collected during the first and the second cruises.

A prominent separation along the vertical axis is also apparent. Two distinct groups emerge with both the 
mined samples (ANOSIM Global $\mathrm{R}=0.477, \mathrm{p}<$ $0.001 \%$ ) and the non-mined samples (ANOSIM Global $\mathrm{R}=0.581, \mathrm{p}<0.001 \%$ ) forming a group that is statistically different from Warwick \& Clarke's (1993) original 50 samples. The vertical separation in the ordination plot is more pronounced for the mined samples than for

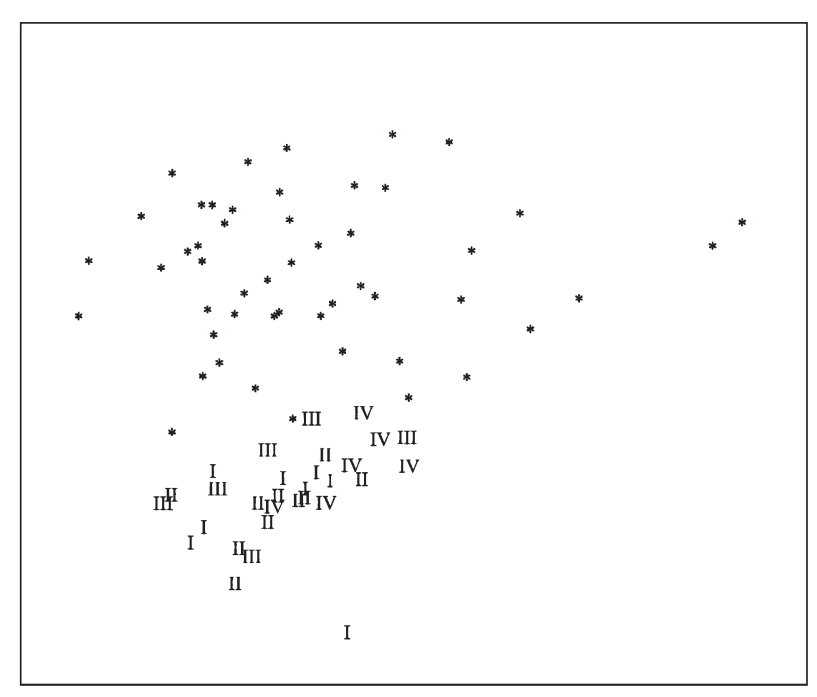

Fig. 3. MDS ordination with the mined southern African samples grouped into their temporal states of post-mining recovery; I: mined less than 1 mo before sampling; II: mined 7 to 9 mo before sampling; III: mined 12 to 24 mo before sampling; and IV: mined $>36$ mo before sampling (Table 1 ). Stress $=0.18$

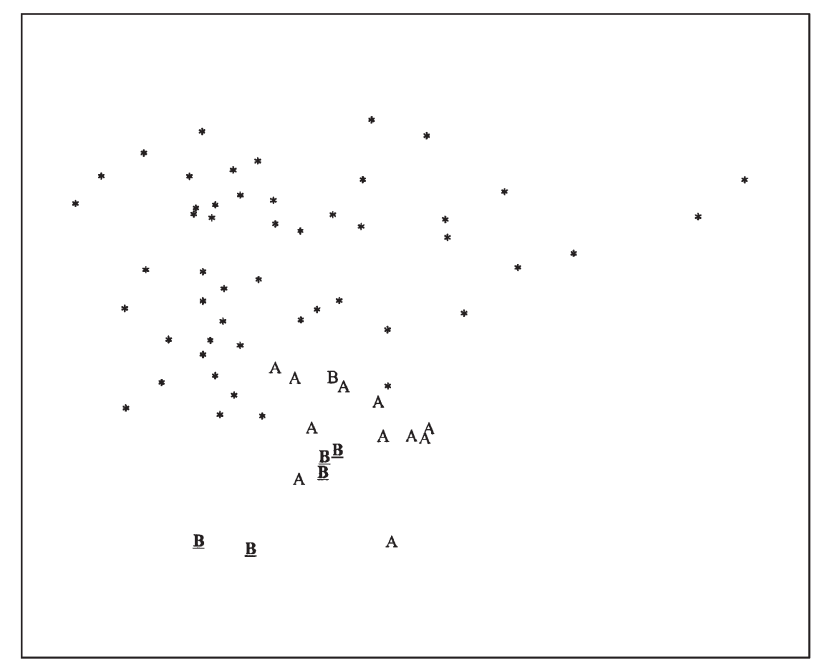

Fig. 4. MDS ordination of the NE Atlantic samples analysed with the southern African samples from the 'before-and-after' mining reference area, Station 1. Samples collected from Station 1 during the first cruise are represented by 'A', and those collected during the second cruise are represented by 'B'. Non-mined samples are printed in normal font. Mined samples are printed in bold text. Stress $=0.17$ the non-mined samples. The latter group of samples shows some overlap with the original data-set, in particular, the Oslofjord samples which experience seasonal anoxia (OB, OC, OD) (Gray et al. 1988), the undisturbed stations at Northumberland (N), Kiel Bay (K), the pre-spill sample from the Bay of Morlaix (M77), and a sample at the unpolluted end of the transect in the Firth of Clyde (C11).

Within the mined group of samples, there was no clear pattern in terms of the recovery time since mining (Fig. 3). Generally, the samples that had over 3 yr of post-mining recovery (category IV) were positioned closest to the NE Atlantic samples in the plot. Macrobenthic samples from areas that had just been mined (category I) were positioned towards the lower end of the ordination, indicating most dissimilarity to the NE Atlantic samples in terms of their phyletic composition.

MDS ordination of the samples from Station 1 merged with Warwick \& Clarke's (1993) original data set, display a shift in community structure from the before to after mining condition (Fig. 4). The nonmined samples collected in 1994, and a non-mined sample collected in 1995 (printed in normal font in Fig. 4), partially overlap with the original data set. Macrobenthic samples collected from the same area 1 mo after mining (underlined and printed in bold font in Fig. 4) exhibit a change in community composition which is expressed as a downward shift along the vertical axis of the ordination plot.

When the mined samples are analysed together with the non-mined samples for each sampling cruise, they jointly cluster together in a group that is significantly different from Warwick \& Clarke's (1993) original data set (Fig. 5). The southern African samples from the first cruise (ANOSIM Global R $=0.530, \mathrm{p}<0.001 \%$ ) and the second cruise (ANOSIM Global R = 0.471, p < $0.001 \%$ ) are significantly different to those obtained off the NE Atlantic Shelf. The horizontal axis of disturbance is conserved with the most grossly polluted NE Atlantic samples stretching to the extreme right of the plot. The mined samples from southern Africa are positioned below the NE Atlantic samples in the ordination, spanning from the 'undisturbed' to the 'moderately disturbed' position, according to Warwick \& Clarke's (1993) classification of perturbation along this axis. The non-mined samples cluster in the 'moderately disturbed' position and are vertically distributed towards the lower reaches of the ordination. There is, however, considerable overlap between the mined and nonmined samples collected off the southern African coast.

The distinction between the NE Atlantic samples and the southern African samples is attributed primarily to 5 phyla: the crustaceans, echinoderms, molluscs, nemerteans, and annelids (Table 2). The Crustacea are 
Table 2. The contribution of each phylum to the average Bray-Curtis dissimilarity between the NE Atlantic samples and the mined and non-mined southern African samples, averaged over all samples. Phyla contributing less than $5 \%$ to the dissimilarity are excluded from this table. Phyla are listed in decreasing order of importance in terms of contributions to dissimilarity for the mined group of samples. The group with the relatively higher average 'production' for each phylum is accented in bold

\begin{tabular}{|c|c|c|c|c|c|c|c|}
\hline \multirow[t]{2}{*}{ Phylum } & \multirow[b]{2}{*}{ NE Atlantic } & \multicolumn{6}{|c|}{ Average production (\%) } \\
\hline & & Mined & $\begin{array}{l}\text { Contribution to } \\
\% \text { Contribution }\end{array}$ & $\begin{array}{l}\text { o dissimilarity } \\
\text { Cumulative \% }\end{array}$ & Non-mined & $\begin{array}{l}\text { Contribut } \\
\% \text { Contribu }\end{array}$ & $\begin{array}{l}\text { dissimilarity } \\
\text { Cumulative \% }\end{array}$ \\
\hline Crustacea & 3.58 & 15.37 & 22.28 & 22.28 & 22.81 & 26.51 & 26.51 \\
\hline Echinodermata & 10.23 & 0.00 & 20.56 & 42.84 & 0.33 & 20.20 & 46.71 \\
\hline Mollusca & 29.20 & 51.69 & 13.88 & 56.72 & 19.30 & 13.46 & 60.17 \\
\hline Nemertea & 1.15 & 0.24 & 11.53 & 68.26 & 0.99 & 11.47 & 71.63 \\
\hline Annelida & 54.08 & 31.40 & 10.94 & 79.20 & 55.20 & 6.92 & 85.93 \\
\hline Sipuculida & 0.31 & 1.21 & 6.42 & 85.62 & 0.27 & 5.37 & 91.00 \\
\hline Cnidaria & 0.35 & 0.00 & 5.68 & 91.31 & 1.10 & 7.38 & 98.38 \\
\hline
\end{tabular}
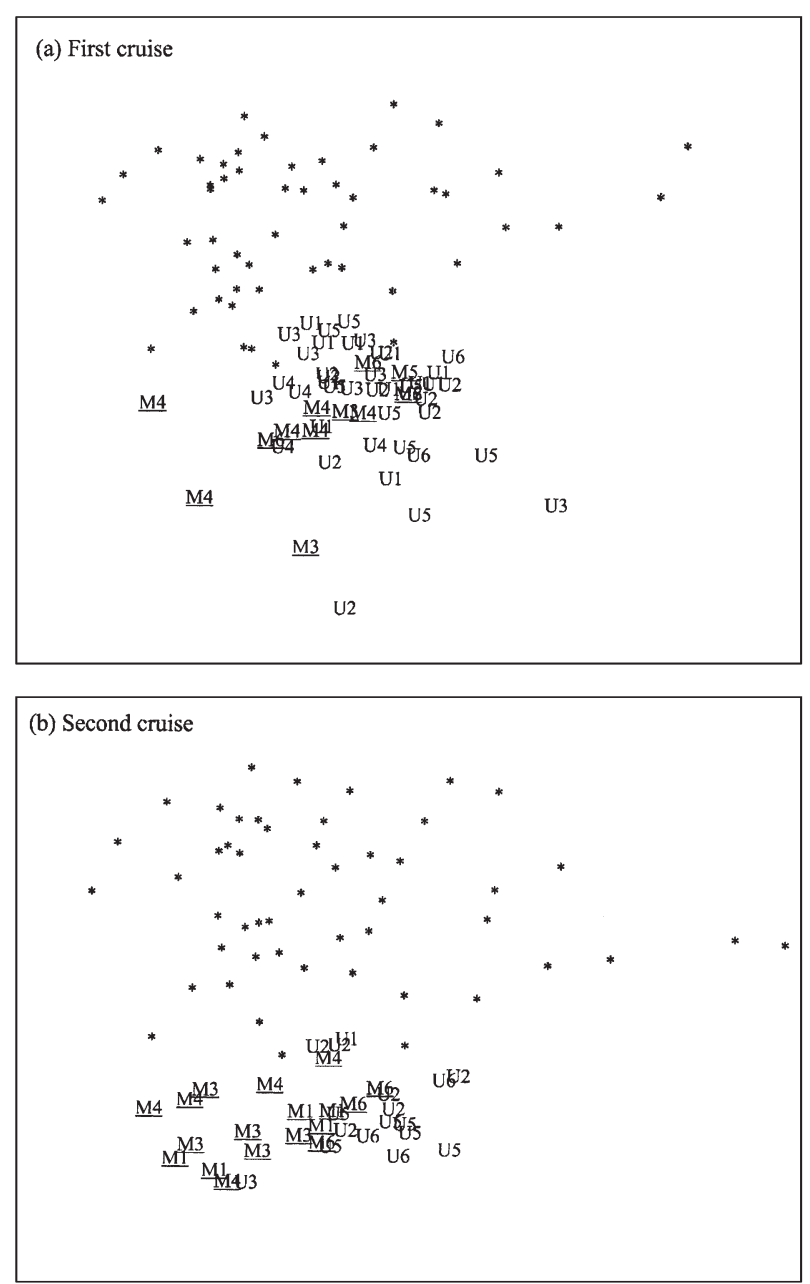

Fig. 5. MDS ordinations for the NE Atlantic samples merged with the mined and non-mined samples from (a) the first sampling cruise in 1994 (stress $=0.17$ ); and (b) the second sampling cruise in 1995 (stress $=0.19$ ). The NE Atlantic samples are represented as asterisks and the southern African samples are represented by their station numbers (1 to 6$)$ and their disturbance status, i.e. whether mined, ' $\underline{\mathrm{M}}$ ', or Cunmined, 'U' responsible for over $20 \%$ of the dissimilarity, being over 4 times greater in the mined samples and over 6 times greater in the non-mined samples compared to the NE Atlantic samples. Conversely, the echinoderms are far more prevalent in the NE Atlantic samples and are virtually absent in the southern African samples; they were not found in the mined samples and were represented by very few individuals in the non-mined samples. Similarly, the nemerteans were more abundant in the NE Atlantic data than in the southern African data. The molluscs, the annelids, and to a lesser extent, the cnidarians, show a difference between mined and non-mined samples. The average 'production' of the molluscs in the mined samples is almost double that for the NE Atlantic and just above half in the non-mined samples. These results indicate a marked increase in the relative proportion of molluscs following mining activity. Conversely, the annelids exhibit a decrease after mining. The average percentage 'production' of annelids in the non-mined samples was approximately equal to that of the NE Atlantic data, yet only about half the 'production' in the mined samples.

Several phyla, namely the Hemichordata, Chordata and Priapulida, were present in the NE Atlantic data but were absent from the samples collected off the southern African coast. Nematoda and Platyhelminthes occurred in the NE Atlantic data and in the non-mined samples but were absent from mined patches.

\section{DISCUSSION}

Offshore diamond mining is likely to impact macrobenthic communities both directly as a consequence of gravel extraction and indirectly due to resuspension, altered sediment granulometry and possible effects from a sediment plume. Newell et al. (1998) reviewed 
the impact of coastal dredging activities on macrobenthos and attributed most of the disturbance to the physical removal of substratum and organisms and partly to the impact of deposition of the dredged material. Direct changes in the community can result from mortality as the sediment is extracted and air-lifted onboard the mining vessel. The relative proportion of annelids decreased by about $50 \%$ in mined areas compared to the non-mined areas and the NE Atlantic samples. Conversely, molluscs exhibited a notable increase in mined patches compared to the adjacent non-mined areas. One plausible explanation, which is supported by personal observations of living molluscs and crustaceans on the diamond sorting sieves after sediment extraction, is that certain robust species survive the mining process and settle back to the seabed with the discarded sediment. Bivalves and gastropods would be prime candidates, and this would account for their rather even distribution on the sea floor once they are deposited there. Thus, the mining activity may result in the selection of species for their physical robustness and tolerance to air exposure rather than their resistance to pollution or disturbance in the more conventional sense. Conversely, the effects of organic pollution are likely to have residual effects with highly organically enriched sediment and possibly contaminating chemicals remaining in the sediment for prolonged periods that may exclude the more chemically sensitive species. This may explain why the disturbed sites from the current study are not dominated by opportunistic polychaetes, as they are in the disturbed NE Atlantic samples and almost all other environmental impact scenarios (Pearson \& Rosenberg 1978, Warwick \& Clarke 1994, Oug et al. 1998, Stark 1998).

MDS ordinations of chemically disturbed samples from the NE Atlantic and physically disturbed samples from southern Africa produced 2 distinct axes. The horizontal axis which assigns the NE Atlantic samples along a scale of increasing perturbation is maintained as the primary axis in the ordination plot. In Warwick \& Clarke's (1993) data set from the NE Atlantic, the large nematodes that are associated with the highly polluted sewage-sludge dump-ground in Clyde, Scotland, play a large part in positioning these samples to the extreme right of the MDS plot. Molluscs, echinoderms and crustaceans have an increasing dominance towards the non-polluted end of the configuration (Warwick \& Clarke 1993) which may account for the grouping of most southern African samples around the 'undisturbed' to 'moderately disturbed' position along the horizontal axis.

A prominent separation along the vertical axis is also recognised with the southern African samples clustered below the NE Atlantic samples in the ordination. This distinction is presumably due to differences in the relative proportions of crustaceans, echinoderms, molluscs and to a lesser extent, annelids. As discussed above, offshore diamond mining is likely to have both direct and indirect impacts on macrobenthic community composition that may be opposed to the impacts of chemical disturbance. The vertical separation is therefore likely due to the high relative abundance of crustaceans in the mined and adjacent areas off the southern African coast compared with the prevalence of annelids in the NE Atlantic data set.

Agard et al. (1993), studying tropical benthic samples on the coast of Trinidad impacted by oil, Tam \& Carrasco (1997), working off organically enriched bays in Central Chile, and Drake et al. (1999), using estuarine samples exposed to organic and inorganic pollution in the Gulf of Cádiz, also found that there was a vertical separation of their samples from the NE Atlantic data. Agard et al. (1993) attributed this distinction to the estuarine character of the region, which may have altered the balance between echinoderms and crustaceans. Drake et al. (1999) suggested that this feature was due mainly to a higher average proportion of crustaceans and annelids, and lower proportion of molluscs and echinoderms in the Gulf of Cádiz. Tam \& Carrasco (1997) attributed the distinction to the oxygen-deficient conditions that are characteristic of the Chilean region. In all these meta-analysis studies, the main difference in community structure was attributed to a smaller proportion of echinoderms and molluscs relative to the NE Atlantic communities and, in the Central Chile and Gulf of Cádiz study, a larger proportion of annelids (Tam \& Carrasco 1997, Drake et al. 1999), and in the Trinidad and Gulf of Cádiz studies, a larger contribution from the crustaceans (Agard et al. 1993, Drake et al. 1999). These latter studies support the findings of the non-mined samples from southern Africa which exhibited a reduced proportion of molluscs and echinoderms but a larger proportion of crustaceans than the NE Atlantic macrobenthic communities. After mining, the proportion of molluscs increases substantially, becoming approximately twice as abundant as found in the NE Atlantic Shelf samples.

Another interesting corollary between the metaanalyses performed in Chile and Trinidad and the current study is that they all show a slight overlap with Stations OB, OC and OD, which were collected in the deep parts of the Oslofjord, Norway, which experiences seasonal anoxia. The west coast of southern Africa, and in particular, the continental shelf off the Namibian coast, experiences a seasonal period of very low oxygen concentrations annually (Chapman \& Shannon 1985). This characteristically oxygendeficient Shelf-water may impose an additional stress on the benthic assemblages that, coupled with the impacts of offshore marine mining, produce a distinct 
macrobenthic community from the communities sampled in the NE Atlantic.

Within the group of southern African samples, the mined samples exhibit a general downward shift in the ordination plot. This distinction is most likely due to a relative decrease in the proportion of annelids and a significant increase in the proportion of molluscs in mined areas. Generally, however, there is much overlap between mined and non-mined samples which, as a group, are distinguished from the NE Atlantic macrobenthos. The congruency between mined and putatively non-mined samples may be explained by 3 possible factors. Firstly, if the region experiences anoxic conditions, the phenomena will affect the whole macrobenthic assemblage. Secondly, the suspended sediments from the mining operation are dissipated also over the areas adjacent to the mined patches, so that these adjacent areas experience a degree of disturbance and share some similarities in terms of community structure with the mined areas. Presumably, the macrobenthic communities in adjacent non-mined areas are able to withstand some smothering from the settling sediments; however, these would be relatively more diverse than in the mined patches, where the community structure is more uniform and almost entirely dominated by bivalves and gastropods. Thirdly, there may be recolonisation of the mined sediments from the adjacent non-mined areas.

Recovery may occur in 2 modes: relatively quickly, by migration of mobile predatory species such as whelks and mantis shrimps, and over a slower time scale by the random settlement of larvae. The appearance of mobile predators that exploit physically disturbed areas to scavenge on injured or dead fauna has been described by Oliver \& Slattery (1985), Britton \& Morton (1994), Kaiser \& Spencer (1994), and Dayton et al. (1995). Nassariid gastropods have been singled out as scavengers that are especially attracted by dead and damaged animals (Britton \& Morton 1995). The whelk Nassarius vinctus occurred in the non-mined areas and was found in particularly high abundance in the mined areas. This robust-bodied and highly mobile gastropod can be hypothesised as 1 possible species that is able to withstand the mining process if air-lifted during sediment extraction and returned to the seafloor and then exploits mined areas to scavenge on damaged or dead fauna. Such a species, which has a relatively large biomass, could contribute significantly to the estimated 'production' value of a sample and hence contribute notably to the congruency in terms of 'production' between mined and non-mined areas in soft sediments.

The observation that the disturbed samples from southern Africa did not arrange themselves along the horizontal axis of disturbance, as defined by Warwick \& Clarke's (1993) data set, does not reflect a failure of the meta-analysis technique to detect disturbance. Rather it shows that the primary axis is strongly determined by the opportunistic species found in organically enriched areas. The structuring factors driving macrobenthic community structure in organically polluted areas are likely to be different to those in physically disturbed areas. Organically enriched areas are typically dominated by high densities of large nematodes (Pearson \& Rosenberg 1978) which played a major role in positioning the grossly polluted samples at the extreme right of the original MDS configuration.

The separation of the NE Atlantic samples on the vertical axis (Figs 2 to 5) suggests that seasonal anoxia may also be an important factor in structuring these benthic communities. This is supported by the overlap with seasonally anoxic Oslofjord samples (Fig. 2). The lack of clear separation of mined from nonmined samples suggests that short-term physical disturbance is less stressful in structuring the macrobenthos over long time periods than longer term anoxia or chemical pollution. These apparently negative results (see Browman 1999) provide useful insight into the relative effects of chemical versus physical disturbance.

The meta-analysis approach was found to be compatible with data collected from other organically polluted areas (Agard et al. 1993, Tam \& Carrasco 1997, Drake et al. 1999) which would suggest a more general spatial applicability than simply the NE Atlantic Shelf. Thus, it would appear that the phylum-level metaanalysis approach offers promise for comparing chemically disturbed macrobenthic communities without the confounding effects of geographic uniqueness. The encouraging aspect of all the meta-analyses performed with Warwick \& Clarke's (1993) baseline study, including the one described here, is that the horizontal axis which assigns the NE Atlantic samples along a scale of increasing chemical perturbation is maintained as the primary axis in the ordination plot. This study shows that phylum-level meta-analysis may not be as useful in separating physically disturbed sites.

Acknowledgements. A special note of thanks is extended to De Beers Marine (Pty) Ltd. who funded the environmental impact assessment and made this study possible. Patti Wickens is thanked for her involvement during the study and comments on drafts of the manuscript. Several people were invaluable in terms of their taxonomic expertise and we extend sincere gratitude for their help. We gratefully acknowledge referees and Ragnar Elmgren for comments on the manuscript.

\section{LITERATURE CITED}

Adams DC, Gurevitch J, Rosenberg MS (1997) Resampling tests for meta-analysis of ecological data. Ecology 78: $1277-1283$ 
Agard JBR, Gobin J, Warwick RM (1993) Analysis of marine macrobenthic community structure in relation to pollution, natural oil seepage and seasonal disturbance in a tropical environment (Trinidad, West Indies). Mar Ecol Prog Ser 92:233-243

Beukema JJ (1988) An evaluation of the ABC-method (abundance/biomass comparison) as applied to macrozoobenthic communities living on tidal flats in the Dutch Wadden Sea. Mar Biol 99:425-433

Bowman MF, Bailey RC (1997) Does taxonomic resolution affect the multivariate description of the structure of freshwater benthic macroinvertebrate communities? Can J Fish Aquat Sci 54:1802-1807

Bray JR, Curtis JT (1957) An ordination of the upland forest communities of Southern Wisconsin. Ecol Monogr 27: 325-349

Brey T (1990) Estimating productivity of macrobenthic invertebrates from biomass and mean individual weight. Meeresforsch 32:329-343

Britton JC, Morton B (1994) Marine carrion and scavengers. Oceanogr Mar Biol Annu Rev 32:369-434

Browman HI (ed) (1999) Negative results. Mar Ecol Prog Ser 191:301-309

Cao Y, Bark AW, Williams WP (1996) Measuring the responses of macroinvertebrate communities to water pollution: a comparison of multivariate approaches, biotic and diversity indices. Hydrobiol 341:1-19

Chapman P, Shannon LV (1985) The Benguela Ecosystem Part II: chemistry and related processes. Oceanogr Mar Biol Annu Rev 23:183-251

Clarke KR (1990) Comparisons of dominance curves. J Exp Mar Biol Ecol 138:143-157

Clarke KR (1993) Non-parametric multivariate analyses of changes in community structure. Aust J Ecol 18:117-143

Clarke KR, Green RH (1988) Statistical design and analysis for a 'biological effects' study. Mar Ecol Prog Ser 46: 213-226

Clarke KR, Warwick RW (1994) Change in marine communities: an approach to statistical analysis and interpretation. Natural Environment Research Council, Swindon

Dayton PK, Thrush SF, Agardy TM, Hofman RJ (1995) Environmental effects of fishing. Aquat Conserv Mar Freshwat Ecosyst 5:205-232

Downing JA, Osenberg CW, Sarnelle O (1999) Metaanalysis of marine nutrient-enrichment experiments: variation in the magnitude of nutrient limitation. Ecology 80:1157-1167

Drake P, Baldó F, Sáenz V, Arias AM (1999) Macrobenthic community structure in estuarine pollution assessment on the Gulf of Cádiz (SW Spain): is the phylum-level meta-analysis approach applicable? Mar Poll Bull 38(11): 1038-1047

Ferraro SP, Cole FA (1990) Taxonomic level and sample size sufficient for assessing pollution impacts on the Southern California Bight macrobenthos. Mar Ecol Prog Ser 67: 251-262

Field JG, Clarke KR, Warwick RM (1982) A practical strategy for analysing multispecies distribution patterns. Mar Ecol Prog Ser 8:37-52

Glass GV (1976) Primary, secondary, and meta-analysis. Educational Researcher 5:3-8

Gray JS, Aschan M, Carr MR, Clarke KR, Green RH, Pearson TH, Rosenberg R, Warwick RM (1988) Analysis of community attributes of the benthic macrofauna of Frierfjord/ Langesundfjord and in a mesocosm experiment. Mar Ecol Prog Ser 46:151-165

Gray JS, Clarke KR, Warwick RM, Hobbs G (1990) Detection of initial effects of pollution on marine benthos: an example from the Ekofisk and Eldfisk oilfields, North Sea. Mar Ecol Prog Ser 66:285-299

Gurevitch J, Hedges LV (1999) Statistical issues in ecological meta-analyses. Ecology 80:1142-1149

Heip C, Warwick RM, Carr MR, Herman PMJ, Huys R, Smol N, Van Holsbeke K (1988) Analysis of community attributes of the benthic meiofauna of Frierfjord/Langesundfjord. Mar Ecol Prog Ser 46:171-180

Herman PMJ, Heip C (1988) On the use of meiofauna in ecological monitoring: Who needs taxonomy? Mar Pollut Bull 19:665-668

Howson CM (ed) (1987) Species directory to British marine fauna and flora. Marine Conservation Society, Ross-onWye

Kaiser MJ, Spencer BE (1994) Fish scavenging behaviour in recently trawled areas. Mar Ecol Prog Ser 112:41-49

Kenkel NC, Orloci L (1986) Applying metric and nonmetric multidimensional scaling to some ecological studies: some new results. Ecology 67:919-928

Kruskal JB, Wish M (1978) Multidimensional scaling. Sage Publications, Beverley Hills

Morrisey DJ, Howitt L, Underwood AJ, Stark JS (1992) Spatial variation in soft-sediment benthos. Mar Ecol Prog Ser 81: 197-204

Newell NC, Seiderer LJ, Hitchcook DR (1998) The impact of dredging works in coastal waters: a review of the sensitivity to disturbance and subsequent recovery on the seabed. Oceanogr Mar Biol Annu Rev 36:127-178

Oliver JS, Slattery PN (1985) Destruction and opportunity on the sea floor: effects of grey whale feeding. Ecology 66: 1965-1975

Olsgard F, Somerfield PJ, Carr MR (1997) Relationships between taxonomic resolution and data transformations in analyses of a macrobenthic community along an established pollution gradient. Mar Ecol Prog Ser 149:173-181

Osenberg CW, Sarnelle O, Cooper SD, Holt RD (1999) Resolving ecological questions through meta-analysis: goals, metrics, and models. Ecology 80:1105-1117

Oug E, Næs K, Rygg B (1998) Relationship between soft bottom macrofauna and polycyclic aromatic hydrocarbons (PAH) from smelter discharge in Norwegian fjords and coastal waters. Mar Ecol Prog Ser 173:39-52

Pearson TH (1987) Benthic ecology in an accumulating sludge-disposal site. In: Capuzzo JM, Kester DR (eds) Oceanic processes in marine pollution. Vol 1. Biological processes and wastes in the ocean. RE Krieger, Melbourne, FL, p 195-200

Pearson TH, Rosenberg R (1978) Macrobenthic succession in relation to organic enrichment and pollution of the marine environment. Oceanogr Mar Biol Annu Rev 16:229-311

Reizopoulou S, Thessalou-Legaki M, Nicolaidou A (1996) Assessment of disturbance in Mediterranean lagoons: an evaluation of methods. Mar Biol 125:189-197

Rogers J (1995) Final report to De Beers Marine (Pty) Ltd on the environmental impact of diamond mining on surficial continental-shelf sediments off Southern Namibia. Report for the Environmental Evaluation Unit, University of Cape Town

Savage C (1996) Multivariate analyses of the impact of offshore marine mining on the benthic macrofauna off the west coast of Southern Africa. MSc thesis, University of Cape Town

Shepherd ARD, Warwick RM, Clarke KR, Brown BE (1992) An analysis of fish community responses to coral mining in the Maldives. Environ Biol Fish 33:367-380

Skalski JR (1995) Statistical considerations in the design and 
analysis of environmental impact assessment studies. J Environ Manage 43(1):67-85

Somerfield PJ, Clarke KR (1995) Taxonomic levels, in marine community studies, revisited. Mar Ecol Prog Ser 127: $113-119$

Stark JS (1998) Heavy metal pollution and macrobenthic assemblages in soft-sediments in two Sydney estuaries, Australia. Mar Freshw Res 49:533-540

Tam J, Carrasco FD (1997) Macrobenthic sublittoral species assemblages from Central Chile along a global scale of perturbation. Gayana Oceanol 5(2):107-113

Vanderklift MA, Ward TJ, Jacoby CA (1996) Effect of reducing taxonomic resolution on ordinations to detect pollution-induced gradients in macrobenthic infaunal assemblages. Mar Ecol Prog Ser 136:137-145

Warwick RM (1986) A new method for detecting pollution effects on marine macrobenthic communities. Mar Biol 92: 557-562

Warwick RM (1988a) Analysis of community attributes of the macrobenthos of Frierfjord/Langesundfjord at taxonomic levels higher than species. Mar Ecol Prog Ser 46:167-170

Warwick RM (1988b) The level of taxonomic discrimination

Editorial responsibility: Otto Kinne (Editor),

Oldendorf/Luhe, Germany required to detect pollution effects on marine benthic communities. Mar Pollut Bull 19(6):259-268

Warwick RM (1993) Environmental impact studies on marine communities: Pragmatical considerations. Aust J Ecol 18: 63-80

Warwick RM, Clarke KR (1991) A comparison of some methods for analysing changes in benthic community structure. J Mar Biol Assoc UK 71:225-244

Warwick RM, Clarke KR (1993) Comparing the severity of disturbance: a meta-analysis of marine macrobenthic community data. Mar Ecol Prog Ser 92:221-231

Warwick RM, Clarke KR (1994) Relearning the ABC: taxonomic changes and abundance/biomass relationships in disturbed benthic communities. Mar Biol 118:739-744

Warwick RM, Pearson TH, Ruswahyuni (1987) Detection of pollution effects on marine macrobenthos: further evaluation of the species abundance/biomass method. Mar Biol 95:193-200

Warwick RM, Clarke KR, Suharsono (1990) A statistical analysis of coral community responses to the 1982-83 El Niño in the Thousand Islands, Indonesia. Coral Reefs 8: $171-179$

Submitted: December 21, 1999; Accepted: February 1, 2001 Proofs received from author(s): September 21, 2001 